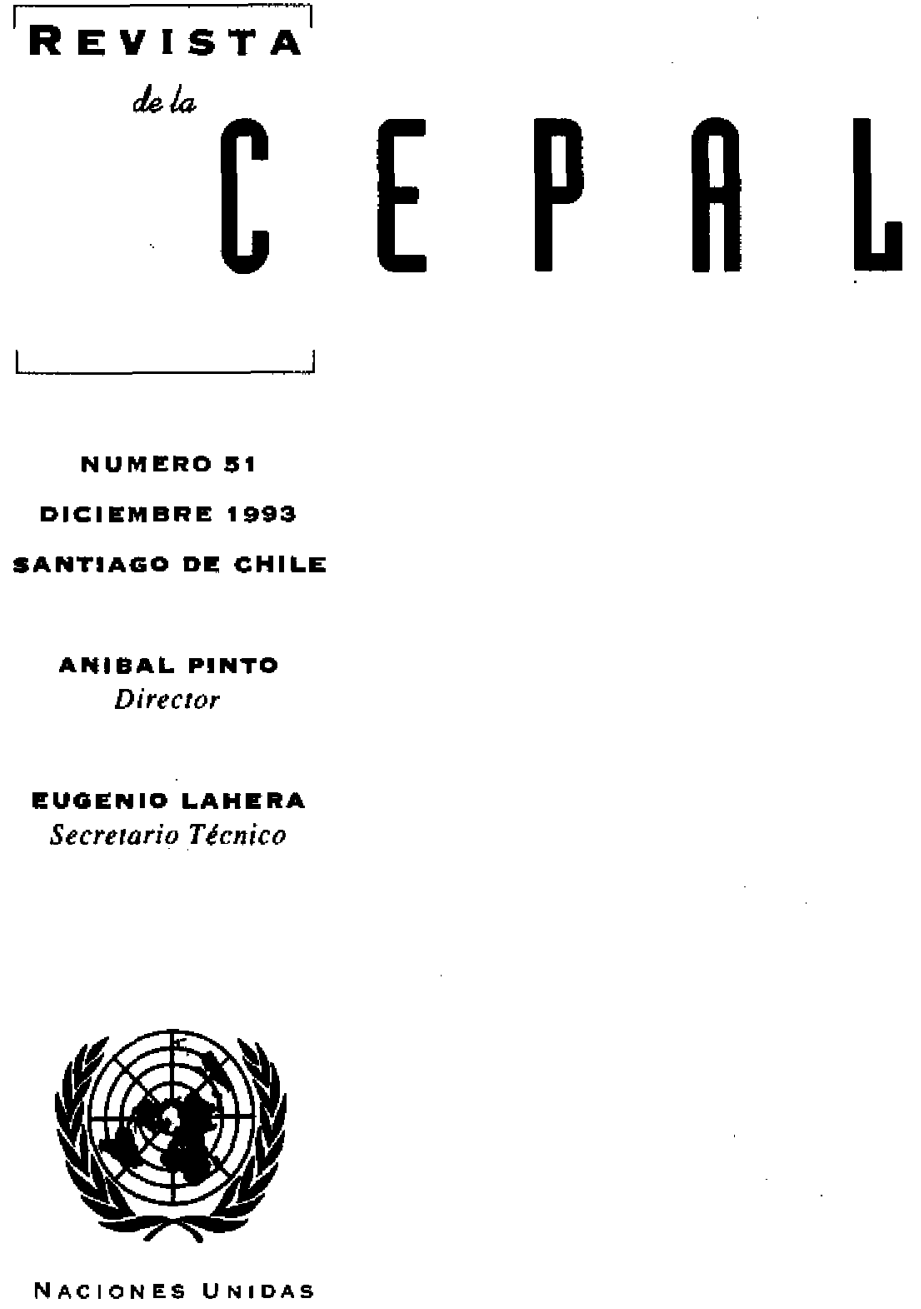


Inauguración de la Sala Fernando Fajnzylber y lanzamiento de la Revista de la CEPAL N² $\mathbf{5 0}$

Gert Rosenthal y Alejandro Foxley

Las transnacionales y la Industria en los paises en desarrollo

Michael Mortimore

¿Dónde estamos en política Industrial?

El desafío de la competitividad Industrial

Rudolf M. Buitelaar y Leonard Mertens

Integración y desintegración social rural

Martine Dirven

Los pueblos Indigenas y la modernidad

John Durston

Productividad y trabajo de la mujer en los Estados Unidos

Inés Bustillo y Nancy S. Barrett

Efectos de las corrientes de capltal sobre la base monetarla

111

Helmut Reisen

Viejas y nuevas políticas comerclales

Daniel Lederman

Integración y desviación de comerclo

Renato Baumann

Integración europea y comerclo latinoamericano

Miguel Izan

El actual debate sobre los recursos naturales

Fernando Sánchez Albavera

Orlentaclones para los colaboradores de la Revista de la CEPAL 


\title{
Los pueblos indígenas y la modernidad
}

\author{
Ser absolutamente moderno es ser \\ aliado de tu propio sepulturero. \\ Milan Kundera, La inmortalidad. \\ No hay una sola forma de \\ modernidad, sino varias, desiguales \\ y a veces contradictorias... El \\ desarrollo modemo no suprime las \\ culturas populares tradicionales. \\ Néstor García Canclini.
}

\section{John Durston}

Oficial de Desarrollo Social, División de Desarrollo Social de la CEPAL.
Numerosos dirigentes e intelectuales indfgenas de la región se preguntan actualmente qué efectos tendrá en su cultura la rápida expansión actual de los principios de libre mercado y la integración de una sola economía mundial. La respuesta depende de qué entendemos por cultura y por modemidad. Las culturas no son conjuntos rígidos de normas y valores tradicionales, sino que tienen una lógica profunda, y una constelación de procesos alternativos que, como un programa computacional en constante cambio, da a cada una de ellos flexibilidad y una gran capacidad de adaptación a las modificaciones en el entorno. La modernidad implica tolerancia y valoración de la diversidad. Las propuestas cepalinas acerca de la competitividad, de los usos actuales del conocimiento y de la imprescindible equidad, dan pautas para que los pueblos indígenas, constituidos en actores sociales, puedan aprovechar las ventajas y evitar las trampas del panorama finisecular. 


\section{I}

\section{Introducción}

Este artículo ofrece una reflexión sobre los contenidos de tres conceptos, los de cultura, conocimiento y modernidad, ${ }^{1}$ y un análisis de lo que estos conceptos significan para el fortalecimiento de los pueblos indígenas de América Latina como actores sociales, económicos y políticos capaces de llevar adelante su propia forma de vencer la pobreza y aumentar su bienestar en sentido amplio.

El análisis se hace sobre la base de la antropología comparativa y del debate actual en la CEPAL acerca de las exigencias de una transformación productiva con equidad en el actual contexto latinoamericano (CEPAL 1990, 1992a y 1992b).

Se parte de una comprobación y de una pregunta angustiada: la comprobación, en las palabras de José Bengoa, de que la expansión inexorable de la economía de mercado es un hecho, un dato de la realidad latinoamericana en los años noventa. $Y$ la pregunta, formulada por diversos dirigentes e intelectuales indígenas, de qué pasará con nuestros valores, con nuestra cultura, en este estilo de desarrollo.

\section{II \\ La crisis de los actores sociales}

Para muchos analistas, los actores colectivos están en crisis en todo el mundo. Caen sostenidamente las proporciones de la población que integran sindicatos o partidos de masas basados en la identidad de clase. Los reemplazan causas que aglutinan temporalmente a individuos de diversas identidades sociales en torno a demandas limitadas a un solo tema (por ejemplo, la causa de la protección del medio ambiente). Asimismo, la planificación y administración global de grandes políticas monolíticas y su implementación por una burocracia nacional están siendo sustituidas con rapidez por la búsqueda de mecanismos más ágiles y flexibles a través de la descentralización y una creciente autonomía regional y local.

En este panorama de cambios en la forma de hacer política en el mundo, el movimiento indígena es casi único, al combinar una causa que recluta individuos de diversas identidades sociales, con el incipiente fortalecimiento de un actor social en el sentido clásico: los pueblos indígenas mismos, organizados y movilizados, que deliberan y actúan colectivamente.

Para participar con éxito como actor social no basta la simple voluntad. Los pueblos indígenas necesitan también de cuatro factores: recursos, alianzas (como ha dicho Víctor Hugo Painemal), un entomo favorable y una estrategia. Para propósitos de análisis, se desarrolla a continuación la tesis siguiente: que Ios recursos fundamentales para el éxito indígena son su propia cultura y la apropiación del conocimiento universal, y que tanto el entorno favorable como las alianzas necesarias para ese éxito pueden surgir de la expansión de la modernidad en el mundo. $\square$ Este articulo es una version revisada de la ponencia presentada al seminario "Pueblo mapuche y desarrollo: desafíos y propuestas", auspiciado por la Organización de las Naciones Unidas para la Agricultura y la Alimentación (FAO) y el Gobierno de Chile, y realizado en Angol, Chile, del 14 al 16 de enero de 1993.

1 La mayor parte de los postulados de este trabajo caben perfectamente en lo que se denomina, en la jerga de moda, la posmodernidad: el rechazo a las certezas fáciles, sean ellas cientificis- tas, tecnologistas, positivistas o ideologicas; la celebración de la multiculturalidad y la interculturalidad, y la humildad frente a la complejidad y la aleatoriedad. Sin embargo, parece linguísticamente absurdo relegar el término "modernidad" a ideas del pasado. Preferimos (como Berman, 1982) mantener vigente esta palabra útil, para referinos a lo actualmente vigoroso que se proyecta hacia el futuro. En otras palabras, intentamos comprender "la modernidad después de la posmodernidad" (García Canclini, 1990). 


\section{III}

\section{La cultura: definiciones y connotaciones}

¿Cómo es posible aseverar que existen condiciones favorables para los pueblos indígenas de la región, dada la progresiva desaparición de las prácticas e instituciones tradicionales en muchas comunidades indígenas, y la disminución del uso del idioma nativo entre los jóvenes, muchos de los cuales han optado por emigrar a la ciudad? La respuesta reside en gran parte en la visión que tenemos de lo que es una cultura.

Es importante, para que nos entendamos, no usar el término cultura para expresar conceptos diferentes o-peor-ideas borrosas. Muchas personas tienen una percepción folclórica de la cultura indígena, y diversos escritores han usado la palabra cultura para significar cosas diferentes. De hecho, hay un debate teónico no resuelto sobre el concepto y una variedad de definiciones de él. Sin embargo, es preciso hacer explícita no sólo la definición sino también los matices y connotaciones del uso que damos al concepto de cultura o a cualquier concepto con el cual pretendamos avanzar en un diálogo.

Hay cierto consenso entre los antropólogos en que toda cultura tiene dos grandes componentes: una visión del mundo, es decir, un conjunto coherente de creencias sobre la realidad, y una visión ética, es decir, una escala de valores que determina actitudes sobre el bien y el mal y un conjunto de normas o reglas sobre el comportamiento correcto de la gente.

Para constituirse en una cultura, esta doble visión -de la realidad y de lo que es correcto-debe ser compartida y transmitida en grupos específicos y concretos de personas, a través de un idioma común. En la antropología de hoy se tiende a separar analíticamente, por un lado, el concepto de cultura (que es un sistema abstracto de ideas no observables en la realidad concreta), y por otro el concepto de estructura social, es decir, el conjunto de las prácticas, costumbres, interacciones regulares e instituciones que existen en la realidad concreta y que son observables como comportamientos de las personas. Puede ser útil -por razones que serán evidentes- distinguir también entre el tema del conocimiento y el aspecto valórico de la cultura. Una cultura -en este último sentido de sistema coherente de valores- es la base ética compartida por las personas que hace posible el fun- cionamiento de todas las instituciones de una sociedad y la interacción de sus miembros. La cultura no es, sin embargo, un conjunto simple e inmutable de reglas que se pueden resumir en pocas palabras. Muchos antropólogos creen que las culturas, aparte de expresarse a través de un idioma, funcionan como idiomas o como programas comparables con los de computación por ser mutables y tener sentencias y rutinas que quedan latentes para manifestarse sólo en circunstancias apropiadas.

Cada cultura es, en esta visión, una construcción mental que tiene una estructura lógica profunda (LeviStrauss, 1962), una gramática no inmediatamente discernible, que gobierna y refuerza los valores expresados y que ofrece reglas diversas para circunstancias distintas. Su enorme variedad de principios o prácticas puede incluso contener elementos incompatibles entre sí, y que sólo entran en acción cuando distintas circunstancias requieren respuestas diferentes. Esta flexibilidad hace posible cierta capacidad de respuesta de las personas y las sociedades ante la gran diversidad de situaciones -algunas totalmente nuevas-que surgen a diario.

En última instancia, es la estructura profunda de una cultura la que determina las conductas e instituciones sociales que toda sociedad necesita. Esta estructura profunda se manifiesta simbólicamente y se aprende en gran medida de manera inconsciente de la madre durante la infancia, a través de leyendas, cuentos, ceremonias, rituales, refranes y dichos; y se refuerza cada vez que los miembros del grupo social realizan una ceremonia o recurren a las prácticas de ayuda mutua, o cuando alguien repite un refrán tradicional.

Por otra parte, todas las culturas cambian y adaptan constantemente sus creencias y normas en respuesta a los cambios que ocurren diariamente en el entorno social, económico e intelectual. En este sentido, no hay culturas tradicionales: ninguna cultura en el mundo de hoy es idéntica a lo que era hace una generación, y ni siquiera a lo que era el año pasado. La cultura, como un "idioma silencioso", evoluciona permanentemente con los cambios en el uso que hacen de ella las personas. El español de Cervantes y el inglés de Shakespeare tienen muchas 
diferencias con las formas actuales de esos idiomas -incluso algunas en sus estructuras profundas-, pero ellas se observan principalmente en el contenido del vocabulario. Sin embargo, el idioma sigue siendo español o inglés, aunque nuestro uso del vocabulario haya cambiado.

Para expresar la mutabilidad de las culturas a través del símil computacional, podemos decir que las culturas, como los programas de computación, pueden incorporar nuevas ideas, principios y procedimientos, con los ajustes del caso en el programa original, siempre que esos cambios no pongan en peligro de desequilibrio total irremediable la lógica interna de la estructura profunda del sistema cultural. Las culturas se recrean y se modifican a diario, en los esfuerzos de sus integrantes por confrontar viejos y nuevos problemas y desafíos. En especial, los individuos de mayor creatividad inventan nuevas formas de expresión y nuevos arreglos sociales, inspirados en sus lecturas de nuevos elementos con la óptica de su propia cultura. Estas innovaciones experimentales son evaluadas por los demás miembros de una comunidad o pueblo, y eventualmente son rechazadas o integradas en la cultura y las prácticas compartidas.

Desde esta perspectiva, está claro por qué no se puede hablar de una cultura superior en relación a otra inferior: las escalas de valores, las religiones, etc., no son intrínsecamente más o menos eficientes o "correctas" en términos universales: cada cultura es la más adecuada para sostener ese sistema social, por haberse desarrollado ambos juntos. Es también la más adecuada para ese grupo humano, porque sus integrantes han incorporado -consciente e inconscientemente- las estructuras profundas de la cultura en la cual fueron criados, en sus propias escalas de valores y en sus propias personalidades, lo cual no significa que cultura alguna haya alcanzado la perfección en su manifestación del momento actual o en alguna de sus expresiones pasadas.

Las culturas no son de por sí superiores o inferiores unas a otras, pero sí están en clara situación de desventaja los grupos humanos que han sufrido la desculturación, es decir, la destrucción o la pérdida total o parcial de la visión del mundo y las normas que guiaban a los integrantes de su medio social de origen. En principio, es posible cambiarse de una cultura a otra, pero es un proceso largo, a veces doloroso, y siempre incompleto. $Y$ cuando la cultura de origen coincide con una identidad étnica que tiene elementos fisiológicos propios, el esfuerzo por asimilar una cultura ajena y de integrarse totalmente en una sociedad dominante marcada por estereotipos racistas está condenado al fracaso.

\section{IV}

\section{¿Qué entendemos por conocimiento?}

\section{Información, herramientas y creenclas}

Dos elementos importantes del conocimiento son la información, por un lado, y el manejo de métodos y herramientas de comunicación y análisis, por el otro. Entre estas herramientas se destacan la lectoescritura y las matemáticas; dominándolas bien se puede acceder con más facilidad a otras herramientas más específicas, como el método científico de análisis, los iđiomas extranjeros y la computación, y se puede incorporar cada vez más información.

Pero conocimiento es también creencia. Solemos caer en el etnocentrismo y pensar que nuestro conocimiento es "saber la verdad", mientras que los conocimientos de otras culturas son simplemente creencias, o peor, supersticiones. Sin embargo, lo que creemos verdad este año con toda seguridad se verá modifica- do el año próximo, y tal vez se descarte totalmente en una década o un siglo más. La esencia del método científico moderno es tener presente que no hay un saber cierto y absoluto sino un conocimiento de hipótesis, las que pueden ser muy ampliamente compartidas por muchas personas muy inteligentes e informadas, pero que están todas siempre sujetas a una posible revisión y mejoramiento.

Como contrapartida del conocimiento que es peculiar a una cultura específica -el "conocimiento local" (Geertz, 1982)-, existe hoy en día un conocimiento universal, acumulado y construido cumulativamente, con los aportes de todos los pueblos, que está disponible para todos y ya ha sido integrado en un gran número de culturas específicas en todas partes del mundo.

Así, el conocimiento particular mapuche incluye un conocimiento específico, por ejemplo, de la ges- 
tión sustentable de ecosistemas del sur chileno, de medicina natural y de formas de cooperación en el trabajo. Estos conocimientos específicos pueden y deben ser compartidos con otros pueblos, escribiéndolos y publicándolos para que así lleguen a formar parte del conocimiento universal.

Por otro lado, esta realidad significa que una cultura dada tampoco puede ser considerada superior a otra por el cuerpo de conocimientos que poseen sus integrantes. Si el conocimiento es un bien universal, entonces es un patrimonio común de la humanidad toda, y es apropiable por cualquier pueblo para ser integrada en su propia cultura. Evidentemente, un pueblo estará en ventaja o desventaja en la correlación de fuerzas, en un momento dado, frente a otros actores sociales con los cuales interactúa, dependiendo de la combinación que haya logrado de la cultura propia y de la cultura universal apropiada e integrada hasta ese momento.

\section{Conocimiento y poder económico en los años noventa}

La nueva importancia económica del conocimiento en este fin de siglo surge especialmente de los cambios en la relación entre conocimiento y producción (Toffler, 1991; CEPAL, 1992a). Hoy, para producir los bienes y servicios se requiere proporcionalmente menos energía y material que en el pasado, y cada vez más conocimiento. Esto significa también que se requiere cada vez menos capital por unidad de producto a medida que aumenta la proporción de información que se usa en su producción y comercialización. El conocimiento está reduciendo la necesidad de materias primas, trabajo manual, tiempo, espacio y capital y se está convirtiendo en. el recurso central de la economía avanzada. Como siempre hay progresos en el conocimiento, la competencia por conquistar mercados significa que el conocimiento es cada vez más el factor productivo escaso, papel que en el pasado correspondía al capital.

Si bien esta descripción de lo que está empezando a suceder en la economía avanzada suena muy lejana de la realidad indígena, hay dos aspectos de ella que sí son pertinentes: uno, que la empresa o el pueblo que tiene los conocimientos requeridos siempre puede atraer capital financiero, y dos, que el conocimiento, a diferencia del capital, no puede ser mantenido como propiedad exclusiva sino que puede ser compartido y cualquiera puede apropiarse de él.

Hoy en día, el conocimiento específico y exclusivo de cualquier cultura ya no basta, por la interpenetración económica y la interconexión comunicacional existentes, para bregar con la complejidad del mundo mayor. Se necesitan los antecedentes y herramientas técnicas del acervo de conocimiento universal, accesible a todos y generalmente sin costo monetario, para que los integrantes de una comunidad o un pueblo puedan tomar decisiones y actuar oportunamente frente a otros actores sociales, reaccionando a cambios acelerados en las condiciones de esa interacción. Para tener la capacidad de actuar en la sociedad mayor, el autoconocimiento cultural profundo tiene que combinarse con un amplio conocimiento del resto del mundo y de las ciencias universales.

\section{V}

\section{La modernidad y los pueblos indígenas}

Contrariamente a lo que se suele decir, la modernidad es mucho más que la adopción de la última tecnología para aumentar la productividad; tiene también aspectos sociales y culturales que son de su esencia. La modernidad implica que el hombre común puede empezar a controlar su propio destino colectivo, a ser el sujeto de su propia modernización (Berman, 1982). En las palabras de García Canclini, la modernidad abarca cuatro movimientos básicos: "un proyecto emancipador, un proyecto expansivo, un proyecto renovador y un proyecto democratizador" (García Canclini, 1990, p. 31). La democracia y la igualdad de oportunidades son entonces aspectos centrales de la modemidad: ni la extrema pobreza de parte importante de la población ni la inequidad son modernas. El modelo económico neoliberal tampoco es moderno, ya que es incompatible con muchos de los postulados éticos básicos de la modernidad que cobran creciente fuerza en el mundo. Lo moderno en el campo de los sistemas económicos no es el capitalismo salvaje y descontrolado que propaga el modelo neoliberal, sino una economía de mercado domada por una sociedad civil activa, con actores sociales que participan en el gobernar de un Estado activo e intervencionista, aunque no agigantado. 
La modernidad también se define por la asunción del conflicto como un aspecto normal de la vida democrática, y por la tolerancia recíproca que permite resolver conflictos sociales sin recurrir a la violencia y la muerte: poco a poco las ideas de tolerancia ante la diversidad, de democracia, de negociación de los conflictos, ganan terreno. La modernidad cultural implica sobre todo el fin de los dogmas, una visión más humilde de lo que realmente sabemos de la compleja realidad humana intercultural, y una gran cautela en proponer o imponer acciones a partir de nuestras propias creencias de lo que es verdadero y lo que es bueno.

Los pueblos indígenas han vivido una larga historia de conflicto y dominación en que sectores de la sociedad y muchos de los gobiernos nacionales los han agredido frontalmente. Ahora, muchos gobiemos y parte de las sociedades nacionales parecen dispuestos a apoyar a esos pueblos en la defensa de su derecho a existir, a tener una cultura propia y a elevar su nivel de vida material. Esta es una situación nueva, favorable a la causa indígena. Es un aspecto de la entrada de América Latina en la modernidad.

En este nuevo contexto, es preciso elaborar formas también nuevas de luchar contra la injusticia y por los derechos legítimos. La confrontación todavía tiene su lugar, pero con un sentido muy diferente: como punto de partida de un proceso de competencia y negociación, como una forma eficaz y dramática de presentar demandas transables.

En cierto sentido, se puede hablar de la modernidad vista como un aspecto de la reciente emergencia de una cultura universal. Además del conocimiento universal, el otro componente de toda cultura -un sistema de valores- también está empezando a encontrar su propia expresión universal y moderna, por ejemplo, en la Declaración Universal de los Derechos Humanos.

Aquí es esencial subrayar un punto sobre el cual todavía hay poca conciencia. No es efectivo que adquirir tecnología y educación formal signifique, para un pueblo indígena latinoamericano, homogeneizarse inevitablemente en la cultura nacional, europea o norteamericana. Por el contrario, la modernidad que cobra creciente presencia en todo el mundo, más que simplemente tolerar la diversidad, la valora y la fortalece. Modernidad es lo que se ha estado haciendo en el movimiento ecológico mundial, $\mathrm{y}$ en la difusión y comprensión cada vez mayor de los derechos de los pueblos indígenas.

En los países económicamente más avanzados, hoy se ve, no la uniformidad cultural pronosticada en décadas pasadas, sino la más heterogénea gama imaginable de culturas y subculturas, en constante efervescencia e intercambio, aunque no siempre en recíproca armonía.

Esta diversidad y este florecimiento de la multiplicidad de culturas que caracteriza a las sociedades centrales es el resultado, en gran parte, de los cambios recientes en el frío mundo de lo económico. Allí la diversidad - tanto genética en los animales y las plantas como cultural entre los pueblos humanos- se valora porque se la percibe como un banco de posibilidades, de recursos potencialmente valiosos como fuente de utilidades para el capitalismo moderno.

Aunque es más que dudoso que los empresarios valoren la diversidad cultural como han aprendido a valorar las potencialidades de la biodiversidad, de todas maneras el empresariado se beneficia de la diversidad cultural de tres maneras: por la riqueza creativa que se traduce en la invención de nuevos productos y gustos; por la producción de bienes culturales y materiales que ya forman parte de las culturas existentes, y por la demanda de sus productos especiales por parte de los integrantes de las diversas culturas. $\mathrm{La}$ gran agilidad de la comunicación y de la respuesta tecnológica en el mercado de hoy hace posible satisfacer gustos y demandas muy especializados en pequeños nichos del mercado mundial. Aunque aún prevalece la producción de bienes en serie y la formación de gustos masivos a través de la publicidad, lo que este mercado busca, más que productos en serie, uniformes o para gustos homogéneos, son producciones infinitamente diversificadas para gustos infinitamente diversos. Si hay demanda de música andina, por ejemplo, habrá capital para que alguna empresa satisfaga esa demanda y obtenga utilidades.

De hecho, el mercado de productos de todo tipo, creado por las culturas afroamericana y latinoamericana, ya es de gran envergadura y brinda ganancias multimillonarias a un sinnúmero de empresas de todos los tamaños. Lo que manda, en este contexto, es el poder de compra, la demanda efectiva; si hay una demanda efectiva, monetaria, para las expresiones creativas de alguna cultura o subcultura por parte de sus integrantes y por los aficionados a ella, esa cultura prosperará.

Parte importante de la demanda efectiva de expresiones culturales indígenas hoy proviene de un sector de la población vasto y amorfo: es esencialmente en los estratos más educados donde la valorización de las culturas indígenas sobrepasa el contexto 
del mercado. Se basa en una conciencia científica y ética moderna, que ha incorporado nociones (claras o borrosas) de la antropología, la ecología y otras vertientes. También su impacto va más allá de la demanda económica efectiva que ejerce, ya que son personas acostumbradas a actuar y a opinar en el debate público, y a influir en las políticas gubernamentales.

Las culturas y las sociedades indígenas actuales no han sido erradicadas en siglos de asedio. Las características esbozadas arriba, de la verdadera modernidad, a medida que ésta se instale (todos dicen querer "modernizarse"), conformarán un marco que en términos netos parece más propicio para la supervivencia cultural y física de los pueblos indígenas. Si el Estado no asedia al pueblo indígena sino que combate el asedio, y si este pueblo se constituye en actor social eficaz partiendo de la fuerza que le da su propia cultura y el conocimiento universal que ha hecho suyo, y si aprovecha las alianzas ofrecidas por los movimientos ecologista e indigenista, podemos pensar con optimismo que florecerá, aunque persista el asedio de la discriminación racial y del lado salvaje, todavía no domado, de la economía de mercado.

\section{VI}

\section{El etnodesarrollo y la modernidad}

\section{El desarrollo social y la reducción de la extre- ma pobreza}

¿Cómo influyen estas concepciones de la cultura, el conocimiento y la modernidad en el desarrollo de los pueblos indígenas? Por un lado, el desarrollo social significa el mejoramiento del bienestar de toda la población en diversas esferas: material, de autovaloración y de realizacion de potencialidades individuales. El etnodesarrollo, en consecuencia, puede ser definido sucintamente como la formulación y realización por una etnia de sus propios objetivos de bienestar y de la estrategia para alcanzarlos.

Por otro lado, uno de los mayores obstáculos para que un pueblo indígena logre el bienestar y la supervivencia de su cultura es la extrema pobreza. Esto es doblemente cierto cuando existen oportunidades para escapar de la pobreza sustrayéndose al sistema económico local que sustenta a duras penas la población y, por ende, la reproducción de la cultura. Si la única perspectiva que ofrece una comunidad indígena a sus jóvenes es la lucha sin descanso por la mera supervivencia, las perspectivas de que esa sociedad y esa cultura sobrevivan son diametralmente distintas que si ofrece una satisfacción digna de las necesidades básicas, sin autoexplotación.

Escaparse de la extrema pobreza, hoy, significa más que reunir los recursos materiales exigidos; significa lograr niveles de productividad suficientes para participar en mercados cada vez más integrados y competitivos.

\section{Una visión simpllsta de la cultura y del desa- rrollo económico}

En general, la relación entre cultura y desarrollo es todavía muy mal entendida. El problema parte del error, señalado antes, de pensar que unas culturas son totalmente superiores a la gran mayoría de las otras. La valoración simplista y etnocéntrica de las culturas propias de las naciones ricas llevó a la persistencia de otro postulado simplista: que desarrollarse quiere decir adoptar los elementos básicos de la cultura noreuropea 0 , posteriormente, de la estadounidense y la japonesa.

Pero hay que tener en cuenta que los Estados Unidos y Japón -y recientemente los llamados "tigres" asiáticos- han desarrollado sus propios modelos productivos, sociales y políticos, partiendo de sus propias culturas e integrando en ellas conocimientos universales de la ciencia y la tecnología, y elementos específicos de organización observados y analizados en diferentes naciones.

Sin ir más a fondo, y a la luz de lo dicho sobre las características de la cultura, se puede deducir de estos ejemplos que la mantención de una cultura propia no sólo es compatible con un aumento de productividad basado en la apropiación de conocimientos universales, sino que es una condición necesaria para que el crecimiento del producto se traduzca en mayor bienestar real de la población. La opción se da entre la modernización "desde adentro", con transformaciones en la cultura propia que no produzca un quiebre sistémico, y la modemización "hacia afuera", en 
un esfuerzo inútil y dañino de identificarse con otra cultura y otro pueblo.

Para poder competir internacionalmente, no sólo se necesitan una alta productividad y una fuerte motivación de las empresas y conglomerados, sino que se requiere un sistema social en el cual todos los grupos y sectores estén, y se sientan, involuctados en el desarrollo del conjunto (CEPAL, 1992a y Toffler, 1991). Es necesario, para ser sistémicamente competitivo, lograr un grado de equidad en la población que asegure tanto la estabilidad sociopolítica a largo plazo como una alta motivación en el trabajo y en el quehacer cívico. Por ende, evitar que sectores enteros de la sociedad queden excluidos de los beneficios del desarrollo y de la toma democrática de decisiones sobre el estilo de desarrollo que ha de seguirse es una condición necesaria de la transformación económica que requiere hoy América Latina (CEPAL, 1992a).

De este análisis de las nuevas exigencias de competitividad surgen tres conclusiones que son relevantes para los pueblos indígenas. Primero, estos nuevos requisitos implican corregir la marginación y el despojo de los pueblos autóctonos dentro de cada Estado nacional. Segundo, estos mismos principios sistémicos pueden ser adoptados como orientación por un pueblo y hasta por una comunidad; esta también tiene que competir, económica y políticamente, con otros actores sociales, aunque en este caso dentro de un mismo territorio y un mismo Estado nacional. En tercer lugar, se puede concluir que los pueblos indígenas tienen ciertas ventajas comparativas: poseen una cultura propia bastante intacta, y hay en ellos un renaciente sentido de identificación del individuo con el destino de su pueblo, y una relativa equidad en la distribución de la riqueza.

Finalmente, los pueblos indígenas pueden ser más competitivos que antes porque ya no son pueblos sin educación formal: por ejemplo, según un estudio reciente en el cual participó la CEPAL a través del Centro Latinoamericano de Demografía (CELADE), sólo el $1 \%$ de los jóvenes mapuches del sur de Chile, entre 10 y 29 años, que viven en reducciones no ha aprobado ningún año de estudio. $Y$ por primera vez, más mujeres mapuches jóvenes tienen educación que los hombres: sólo el $0.8 \%$ de ellas, contra el $1.5 \%$ de los varones jóvenes, carece de estudios formales (CELADE/ INE/Universidad de la Frontera/Instituto Indígena/ PAESMI, 1990). Estas tendencias positivas se repiten en Bolivia, Perú y muchos otros países de la región (CELADE, 1992). En muchas sociedades indígenas, las mujeres constituyen un recurso valioso hasta ahora subaprovechado. Además de su nueva educación formal, la secular capacidad de la mujer indígena para administrar los recursos del hogar y su actitud de servicio sin ambiciones personales deberían ser útiles en los nuevos esfuerzos por crear instancias de autogestión comunitaria y de deliberación colectiva. Aprovechar este potencial significaría cambiar en algún grado las relaciones interpersonales, la institucionalidad del hogar y algunos elementos de la cultura indígena. Es un tema digno de ser analizado a fondo, especialmente por los varones indígenas.

No debe perderse de vista, sin embargo, que la cantidad de conocimiento universal que han adquirido ya por apropiación los pueblos indígenas va a la zaga del adquirido por otros sectores o actores sociales con los cuales tienen que competir. Esta disparidad, más que reflejar algún umbral "necesario" de conocimiento para el desarrollo, significa una desventaja que es preciso reducir de manera progresiva y permanente.

\section{El conocimiento para la competencia política y la negoclación}

Por otra parte, los principios y las armas de la competitividad moderna se aplican no sólo en la economía; la competitividad es también parte de la esencia de los movimientos sociopolíticos exitosos. En la región, incluso allí donde la sociedad dominante persiste en pretender asimilar a la población indígena, la castellanización, la profesionalización y la penetración de los medios de comunicación tienen en gran parte un efecto de bumerán: funcionan como recursos y como vehículos de una mayor concientización, y están conduciendo a una revalorización de la cultura propia y "a una mayor audacia y globalidad de las ahora llamadas naciones indias en sus planteamientos" (Albó, 1991, pp. 330-331).

Uno de los usos competitivos no económicos del conocimiento es el que se da en los litigios judiciales -por tierras, por discriminación racial, etc.-, que son en cierta medida una forma de competencia: en ella la parte que cuenta con la mejor preparación de antecedentes y la mejor comprensión del funcionamiento del sistema judicial y legal tiene la mayor esperanza de ganar. Por otro lado, el manejo de aprendizajes que incorporan numerosos y variados elementos del conocimiento universal es especialmente valioso para enfrentar incursiones de entidades extrañas a la comunidad, que persiguen fines de lucro dentro de las normas legales vigentes y con las cuales hay que lle- 
gar a algún acuerdo o a las cuales hay que saber frustrar, al amparo de la ley.

Para eso se requiere también perfeccionar una destreza que hasta hace poco no se estudiaba: la negociación, sea para encontrar una salida aceptable para ambos contrincantes, sea para lograr alianzas efectivas con otras fuerzas sociales. La técnica de la negociación ha sido estudiada en diferentes contextos en diversas partes del mundo. Aunque cada cultura tiene sus propias formas de negociación, los principios abstractos, presentados en forma didáctica, forman un conjunto de habilidades que se puede aprender. Puesto que cada pueblo y cada comunidad indígena compite $-\mathrm{y}$ tiene que convivir- con otros actores sociales, estas habilidades pueden ser muy valiosas para negociar mejor, por ejemplo, con la comunidad aledaña, para negociar derechos de agua con empresas o sectores sociales no indígenas, para negociar derechos compartidos sobre territorios, bosques y minerales del subsuelo, o para mejorar alianzas y plataformas políticas con otras fuerzas indígenas y no indígenas.

\section{4. ¿Qué hacer?}

Ha llegado el momento de replantear, a la luz de estos diversos antecedentes, la pregunta inicial. Pero en vez de preguntarse qué pasará, de manera pasiva, reactiva, lo que debe preguntarse es qué puede hacerse para aprovechar las aperturas y alianzas que el estilo de desarrollo emergente en la región ofrece a los pueblos indígenas y sus culturas, y al mismo tiempo prepararse para encarar los grandes riesgos que éste también trae consigo. Por cierto, no se trata de dar recetas sino de reflexionar sobre algunas de las connotaciones del análisis precedente.

De él se puede concluir, en primer lugar, que aumentar la educación formal es un paso fundamental. La educación universal, en este contexto, significa que todas las personas de una etnia aprendan bien su idioma, su propia historia, las técnicas tradicionales de manejo del ecosistema local, su medicina natural, sus normas y valores, su religión y el funcionamiento de sus instituciones sociales y prácticas de reciprocidad. Más allá del discurso que valora la cultura indígena, se trata de transmitir la cultura misma. Puede ser preferible que el sistema educativo oficial ceda esa función a los sabios y sabias locales en vez de intentar la elaboración de un texto estándar que logre interpretar fielmente esta compleja y sutil construcción mental, parte de cuya riqueza pueden ser sus variaciones locales. Base imprescindible es el aprendizaje cabal del idioma nativo, que contiene la estructura lógica de la forma de pensar propia, además de una infinidad de expresiones idiomáticas que reflejan y transmiten la visión del mundo y los valores de la cultura propia.

Pero la educación universal también significa saber leer bien, y analizar críticamente lo que aparece en la televisión y en la radio sobre economía, política y cultura. Significa que muchos jóvenes indígenas vayan a la universidad, para alcanzar posiciones de importancia en la sociedad nacional o para servir después a sus comunidades y movimientos con análisis profesionales y conocimientos técnicos. Significa que estudien su propia historia como historiadores profesionales, no para repetir una sola verdad definitiva y aprendida, sino para desarrollar hipótesis cada vez más nuevas, fundadas en datos nuevos, y para entender cada vez más a fondo la historia y la cultura de su propia etnia. Significa que la nueva generación indígena, junto con una profunda valorización de su propia identidad y tradición, comprenda los cambios científico-tecnológicos, económicos y políticos del mundo en que su pueblo tiene que vivir. $Y$ significa que los no jóvenes también sigan aprendiendo en forma permanente, usando la lectura y el estudio para seguir haciendo suyos los elementos del conocimiento universal. Lo esencial es que esa apropiación se haga desde la cultura propia, que sea ésta la que se modernice, seleccionando los elementos nuevos que se desee integrar.

\section{VII}

\section{Algunas reflexiones finales}

Lo que se ha postulado aquí, como se advirtió al principio, es un argumento intencionalmente optimista, para promover el debate. La última palabra está lejos de haberse dicho: hay datos empíricos que reve- lan que el asedio multifacético a las culturas indígenas sigue debilitando instituciones, prácticas y autoimágenes en numerosos casos concretos. Es preciso, entonces, relativizar la visión optimista y acercarla a 
la compleja, contradictoria y poco comprendida realidad: una tarea que habrá que proseguir en forma urgente y sostenida.

\section{La cultura: imperfecta y abstracta}

Hemos visto que ninguna cultura es superior o inferior a las demás, que cada cultura es "la mejor" sólo para ese pueblo. Pero este principio tiene un corolario: ninguna cultura es perfecta. Es necesario tener presente esta verdad para que el indianismo no se transforme en un etnocentrismo o racismo al revés. La idealización de la manifestación actual o pasada de una cultura es un grave error, primero, porque toda cultura entra en alguna contradicción con los principios de los derechos humanos según los cuales el valor superior, en esta nueva cultura universal, es el bienestar de todas las personas. En segundo lugar, en un mundo que siempre ha estado en cambio, y en el cual también las culturas están siempre en cambio, la sobrevaloración acrónica de una manifestación pasajera de una cultura niega precisamente la fuerza que nace de la recreación permanente y mutante de ella. En tercer lugar, las personas que recrean sus culturas reaccionando a estos cambios son falibles, y a veces dan respuestas ineficaces; ante esta posibilidad de error se requiere una retroalimentación de información y reflexión, y correcciones oportunas en un proceso de ensayo y error que es parte importante de la supervivencia de las culturas.

En el análisis del cambio cultural es fundamental no cosificar la cultura, que a fin de cuentas es una abstracción, no un ente pensante con capacidad propia de acción. No es correcto decir que la cultura tradicional es sabia; son las personas las que saben usar $\rightarrow 0$ no $\rightarrow$ sus culturas. Se hace necesario entonces corregir la posible impresión de que es la cultura la que reacciona a los cambios en el medio. Quienes reaccionan a los cambios son las personas, usando, eso sí, los valores y conocimientos de su cultura para tomar decisiones y para actuar. $\mathrm{Y}$ las personas se pueden equivocar; pueden no actuar, o actuar de una manera que lleve al debilitamiento de las instituciones propias, de las prácticas que sostienen a la organización social, y de las formas de transmisión y reafirmación de la cultura.

\section{Los obstáculos al resurgimiento Indígena}

Es esencial, entonces, no exagerar ni dejar la impresión de que el florecimiento cultural y el bienestar material de los pueblos indígenas están garantizados. Existen por lo menos tres tipos de obstáculos potenciales para que eso suceda, los que tienen que ver con la incorporación de elementos de la cultura universal, la consolidación de un contexto y un ethos de modernidad, y los impactos culturales de nuevas relaciones económicas.

\section{a) La incorporación de elementos \\ de la cultura universal}

Las normas y los valores de una cultura se apoyan en las creencias sobre la realidad y sobre las fuerzas que operan en el mundo, para bien o para mal de los seres humanos. Evidentemente, es posible que muchos elementos del conocimiento universal contradigan la cosmovisión de una cultura dada, sobre todo si ella tiene pocas raíces comunes con la europea. Existe el peligro real de que implantar nuevas creencias, en forma sistemática y total, debilite el sistema cultural valórico y, por ende, el sistema social del pueblo que incorpore muy rápidamente una gran cantidad de conocimientos nuevos.

Pero la sicología humana admite la coexistencia de dos formas de creencia: una basada en la evidencia y en la deducción, y la otra basada en la fe. Es perfectamente factible conciliar un gran conocimiento científico moderno con la fe religiosa. Las curaciones médicas basadas en la fe cristiana también abundan entre personas totalmente integradas a la cultura occidental y al conocimiento universal. Puede suponersè entonces que las religiones indígenas de las Américas también pueden coexistir y prosperar con la incorporación del conocimiento universal a sus propios marcos culturales.

\section{b) La consolidación limitada de la modernidad}

La modernidad sociocultural está aún lejos de consolidarse en el mundo. Por ejemplo, todavía no está muy difundida la tolerancia entre distintas etnias y culturas como base de la competencia pacífica y democrática. Esto encierra dos problemas, uno que es evidente y otro que quizás lo es menos. El problema evidente es que persisten amplios sectores retrógrados que promueven el orden basado en la represión de las opiniones diferentes y la mantención de desigualdades en el bienestar y en el poder de decisión. Esto dificulta la estrategia de preservación de la cultura propia y de reducción de la pobreza. En sus contactos con indígenas, los integrantes de la sociedad dominante transmiten sus estereotipos cul- 
turales, que en contextos "premodernos" incluyen la imagen de la cultura indígena como expresión de barbarie. La potencia de esa cultura dominante -por el conocimiento universal que le ha sido incorporado más que por méritos propios- ha hecho que muchos individuos indígenas sientan desvalorizada su identidad y deduzcan que los estereotipos y prejuicios raciales de esa cultura son tan correctos como sus conocimientos prácticos. Y quizás sean aún más dañinos los actores de la sociedad dominante que quieren ayudar al indígena "civilizándolo". La clave para combatir este efecto profundamente nocivo en el bienestar sicosocial y en el vigor de las culturas indígenas es, en gran parte, el fortalecimiento de la visión ético-científica moderna dentro de la sociedad no indígena y una mayor conciencia, entre los integrantes menos educados de la sociedad dominante, del valor y la dignidad de la cultura indígena. Además, para combatir los efectos de los prejuicios raciales de la sociedad dominante, el movimiento indígena puede multiplicar lazos con instituciones que refuercen el sentido de identidad y la autoestima indígenas como condición necesaria del progreso econónico.

El otro problema, menos evidente, que origina los límites actuales de la modernidad y la persistencia de la intolerancia es el siguiente: si bien la autovalorización es esencial para el bienestar síquico, también colinda con el surgimiento de actitudes despectivas hacia otras culturas. Sobre todo para aquellas personas cuyas propias culturas han sido discriminadas y denigradas por grupos dominantes, el etnocentrismo reactivo y el racismo al revés son peligros reales. Las secuelas de estos racismos están a la vista todos los días en las noticias. Se manifiesta actualmente en el sufrimiento causado por el fanatismo de Sendero Luminoso en la población indígena del Perú, en la atroz guerra intercultural en la ex Yugoslavia, en los ataques de grupos neonazis en Europa y en las matanzas fratricidas entre grupos religiosos en la India.

\section{c) Los efectos culturales de nuevas relaciones económicas}

Toda innovación en las relaciones económicas de un pueblo claramente tiene un impacto en la cultura. $Y$ es que las culturas también se expresan y se refuerzan a través de las relaciones económicas de producción y distribución. Al cambiar cultivos anuales por cultivos permanentes, por ejemplo, se elimina la razon de ser de muchas formas de trabajo recípro- co y de rituales asociados con la renovación anual del ciclo vital de la siembra, la lluvia, la cosecha, el trillaje, etc. Un centro turístico puede generar empleo remunerado, pero tal vez lo haga en condiciones de servilismo o de "objeto fotogénico", con daños que no son triviales.

En el fondo, cabe preguntarse qué tan frágiles son las culturas indígenas, o cuál es su capacidad de adaptación al cambio. Se ha argumentado aquí que las culturas en general son más flexibles de lo que generalmente se cree. Las actuales culturas indígenas americanas, en especial, han conservado su vigor a pesar de su historia: está claro que son especialmente "duras de matar", en parte porque se han convertido en culturas de resistencia.

Pero no todas las culturas originarias de América han podido resistir, ni todas las que existen actualmente se pueden calificar de vigorosas, especialmente en la generación joven. $Y$ no se puede generalizar en relación a situaciones muy específicas, cada una de las cuales debe ser analizada en su contexto, obviamente por la comunidad involucrada, para que ella decida al respecto. ¿Cuál será el impacto en la cultura de una nueva propuesta de producción? ¿Es aceptable ese impacto, o tiene un costo superior al beneficio material? ${ }_{i}$ Cómo se puede renegociar la propuesta para que sea menos daffina en lo cultural? La verdad es que estas son preguntas difíciles de responder aun cuando se disponga de todos los antecedentes. Sobre todo en casos de pobreza absoluta, de sobrevivencia a duras penas, es posible que muchas personas tiendan a aprovechar cualquier oportunidad de mejorar sus ingresos, de aliviar su situación límite apenas soportable, sin dudar ni reflexionar.

Por supuesto, la decisión de aprovechar o no una potencial innovación económica corresponde a la comunidad misma a través de sus instituciones decisorias. La retroalimentación informativa y la corrección de las decisiones son guiadas por la cultura, pero obviamente son acciones de personas falibles, sea como individuos, como familia, o en forma colectiva como actor social. Las comunidades o movimientos indígenas deberían hacer un seguimiento permanente de lo que ocurre en el medio, y acopiar, analizar y discutir la información disponible. Asimismo, debería haber procesos periódicos de decisión colectiva, y un diálogo permanente con los principales interlocutores, sean éstos aliados o adversarios (ninguno de los cuales se puede calificar a priori de opositor incondicional). 


\section{Instancias de decisión y acción}

Para la toma de decisiones y la acción a nivel local se requieren instancias institucionales donde los temas puedan ser debatidos; si no existen hay que inventarlas, pero sin importar modelos de otras culturas ni imponer alguno ideado por el liderazgo indígena nacional. Por lo general, las formas específicas que ellas asumen tienden a surgir espontáneamente en cada grupo local en respuesta a la necesidad de crear instancias que cumplan con estos propósitos y con algunas condiciones básicas comunes.

La respuesta a la pregunta angustiante de "qué hacer" surge de la comunidad y del medio local, pero el movimiento indígena a nivel nacional puede crear condiciones generales que favorezcan la activación comunitaria, y dar apoyo a procesos locales específicos para influir en esa respuesta. Un ejemplo es la constitución de comisiones para influir en el debate político nacional; otro es la selección por consenso mayoritario de un solo alfabeto para uso a nivel nacional.

En las comunidades indígenas o el movimiento nacional estructurado, como en cualquier instancia que toma decisiones de envergadura, puede ser muy útil contar con asesorías externas. Especialmente valiosa puede resultar la antropología social de apoyo (Colombres, 1982), en la que antropólogos y otros profesionales, ojalá indígenas ellos mismos, provean de análisis y de elementos de juicio a los consejos de pueblos indígenas para que éstos puedan tomar las mejores decisiones frente a los cambios, oportunidades y peligros del medio económico y político. Las asesorías de especialistas, de hecho, son prácticas típicas de la modernidad, formas de aprovechar conocimientos universales especializados cuya internalización por líderes individuales o por las bases de un pueblo en su conjunto sería ineficiente o demorosa. Los organismos no indígenas que pretenden apoyar la causa indígena, por su parte, necesitan aún más de análisis sobre los efectos de su ayuda en la cultura y las instituciones sociales de la población indígena afectada, si no quieren correr el riesgo de causar más daño que beneficio en la calidad de vida -entendida en un sentido amplio- de esa población.

En resumen, parece inevitable que las culturas indígenas cambien, como han cambiado siempre para responder mejor a nuevas exigencias, sean éstas amenazas u oportunidades. Pero no es inevitable que desaparezcan, por lo menos si se aplica el conocimiento propio y universal en una perspectiva de desarrollo de la propia cultura, si se sigue de cerca la evolución del entorno y si se actúa frente a los cambios negativos y positivos en él.

\section{Bibliografia}

Albó, Javier (1991): El retorno del indio, Revista andina, año 9, $N^{\circ} 2$, Cuzco, Perú, diciembre.

Berman, Marshall (1982): All That is Solid Melts into Air: the Experience of Modernity, Nueva York, Penguin Books.

Colombres, Adolfo (1982): La hora del "bárbaro": bases para una antropología social de apoyo, Puebla, México, D.F, Editora Premia.

CELADE (Centro Latinoamericano de Demografia) (1992): América Latina: información censal sobre pueblos indigenas, $B o$ letín demografico, año XXV, $\mathrm{N}^{\circ}$ 50, LC/DEM/G, 125, Santiago de Chile, julio.

CELADE/Instituto Nacional de Estadisticas/Universidad de la Frontera/Fundación Instituto Indígena/Programa de Apoyo y Extensión en Salud Materno Infantil (1990): Censo de reducciones indígenas seleccionadas: analisis sociodemográfico, Santiago de Chile, CELADE.

CEPAL (Comisión Económica para América Latina y el Caribe)
(1990): Transformación productiva con equidad, Santiago de Chile. Publicación de las Naciones Unidas, $\mathrm{N}^{\circ}$ de venta S.90.II.G.6.

(1992a): Equidad y transformacion productiva: un enfoque integrado, LC/G.1071 (SES. 24/3), Santiago de Chile.

(1992b): Educación y conocimiento: eje de la transformación productiva con equidad, LC/G.1702- Rev. 2, Santiago de Chile, $\mathrm{N}^{0}$ de venta S.92.II.G.6.

García Canclini, Néstor (1990): Culturas hibridas: estrategias para entrar y salir de la modernidad, México, D.F., Grijalbo.

Geentz, Clifford (1982): Local Knowledge: Further Essays in Interpretative Anthropology, Nueva York, Basic Books.

Levi-Strauss, Claude (1962): La pensée sanvage, París, Plon.

Toffler, Alvin (1991): Power Shift: Knowledge, Wealth and Violence at the Edge of the 21 st Century, Nueva York, Bantam Books. 